\title{
Sweat gland tumor (Eccrine Porocarcinoma) of scalp: A rare tumor
}

\author{
Roshani E. Rana, Sachin S. Verma, Vinita A. Puri, Amresh S. Baliarsing \\ Department of Plastic surgery, Seth G. S. Medical College and K.E.M. Hospital, Mumbai, India
}

Address for correspondence: Dr. R. E. Rana, Department of Plastic Surgery, Seth G.S.Medical College and K.E.M. Hospital, Parel, Mumbai - 400 012, India. E-mail: infoplasticsurgery@gsmc.edu

\section{ABSTRACT}

Eccrine Porocarcinoma is a rare neoplasm arising from sweat glands. It was first described by Pinkus and Mehregan as 'Epidermotropic eccrine carcinoma'. It may occur de novo or as a malignant transformation of an eccrine poroma. It is commonly found in older age group and in the lower extremities. Clinically, it may present as a verrucous plaque, polypoid growth or an ulcerative lesion of long duration. Local recurrence and metastasis to skin, lymphnodes, viscera, and bone may occur. Treatment is wide local excision. Metastatic lesions can be treated with chemotherapy. We report a case of eccrine porocarcinoma of the scalp in a 50 years old female who presented to us with a bosselated, firm, painless, non-tender, freely mobile swelling over left fronto-parietal region of 12 years duration. It was excised and histopathological diagnosis was Eccrine Porocarcinoma. In literature, scalp porocarcinoma is a very rare tumor.

\section{KEY WORDS}

Sweat gland carcinoma, eccrine carcinoma, porocarcinoma of scalp.

\section{INTRODUCTION}

ccrine porocarcinoma is a very rare tumor and those arising from the scalp, are still rarer, with very few cases reported in literature. It was first described by Pinkus and Mehregan in 1963 as an "Epidermotropic eccrine carcinoma". ${ }^{1}$ It has also been described as malignant hidroacanthoma simplex, sweat gland carcinoma, malignant intraepidermal eccrine poroma, eccrine poroepithelioma, dysplastic poroma, malignant syringoacanthoma and porocarcinoma. ${ }^{1-3}$

\section{CASE HISTORY}

50 years old female presented to us with a bosselated swelling, of 12 years duration, over left frontoparietal region [Figure 1a, 1b]. It was firm, painless, non-tender and freely mobile. There was no evidence of involved lymph nodes or distant metastasis. CT scan showed a lobular supratentorial lesion within the scalp to the left of the midline showing nodular foci of calcification and cystic or necrotic component. There was no bony erosion and no intracranial extension. Fine needle aspiration cytology was suggestive of a skin adnexal tumor with baseloid sebaceous and focal squamous differentiation and a biopsy was advised. Biopsy reported a malignant skin adnexal tumor of eccrine (sweat gland) derivation (Eccrine porocarcinoma).

Wide local excision was done. Pericranium was free of 
tumour [Figure 2]. The resultant defect was covered with a split-thickness skin graft [Figure 3]. Cut section of the swelling showed yellowish white tumor with few yellow areas and few areas of haemorrhage. Few areas showed cystic changes. Microscopic examination showed an infiltrating tumor with frequent abnormal mitosis. There was lobular configuration and glandular and cribriform pattern. Foci of necrosis, keratinization and mucinous metaplasia of stroma were present. Surgical margins and base were free of tumor. The histopathological diagnosis was malignant skin adnexal tumor of eccrine (sweat gland) derivation.

\section{DISCUSSION}

Eccrine Porocarcinoma is a rare neoplasm arising from

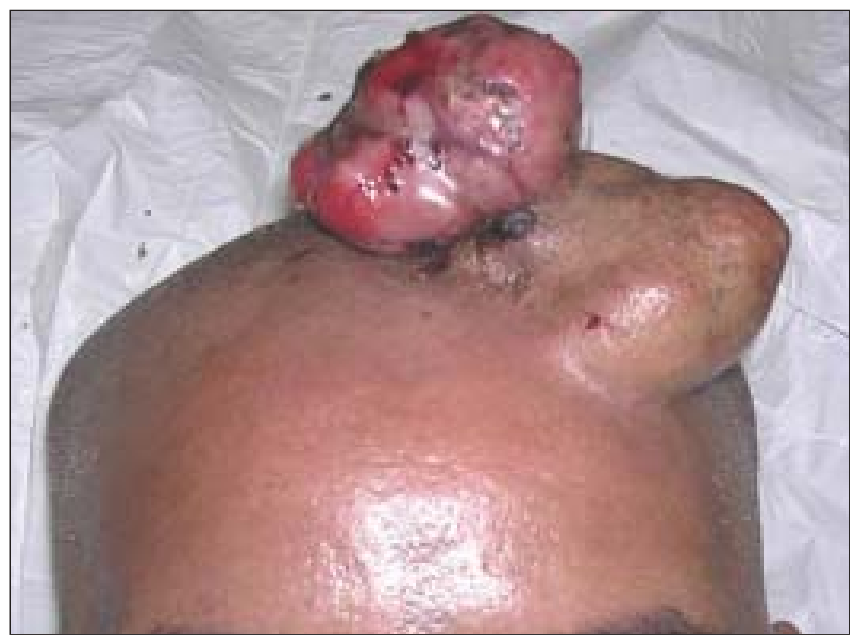

Figure 1: Swelling from front

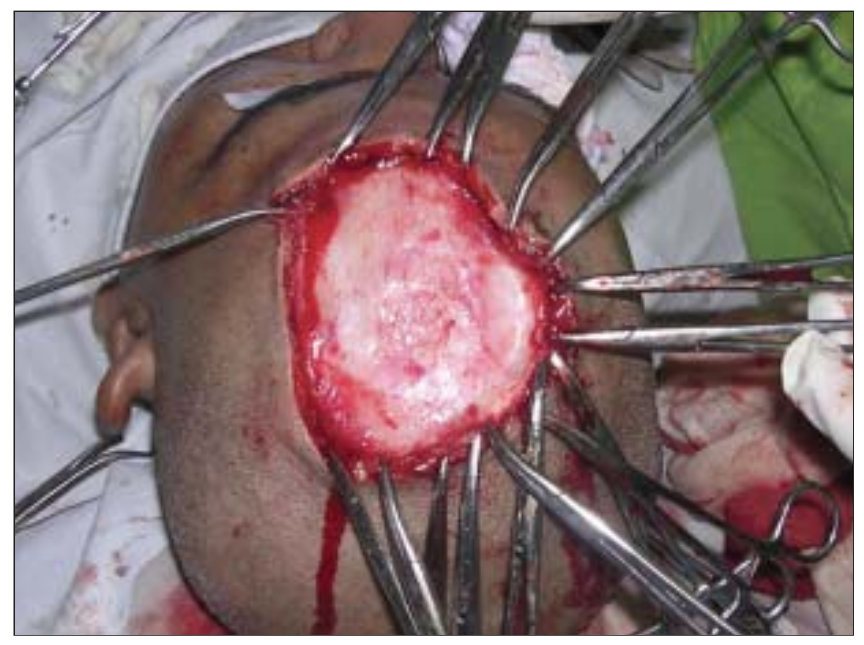

Figure 2: After excision sweat gland. It originates from intraepidermal and upper dermal eccrine ducts.

It may arise de novo or develop as a malignant transformation of an eccrine poroma, nevus sebaceous, chronic lymphatic leukaemia and actinic lesions. ${ }^{1}$ It is commonly found in old people. Usually there is a history of long duration. There is no sex predilection. It is usually located in the lower extremities (more than $50 \%$ ) but rarely may occur on scalp, face and ear $(<20 \%)$, upper extremities $11 \%$, trunk and abdomen 9\%. ${ }^{1}$ There are reports in literature with different presentations, namely, scalp, ${ }^{1,2}$ ear, ${ }^{3}$ cheek, ${ }^{3}$ nose, ${ }^{3}$ scapular region, ${ }^{4}$ back,${ }^{5}$ hand ${ }^{6}$ and leg. ${ }^{1}$

Matloub ${ }^{2}$ reported a case of ulcerative porocarcinoma of occipital region involving pericranium. Ritter et $\mathrm{al}^{1}$ have reported one case of eccrine porocarcinoma in occipital region with intracranial extension. They mentioned 6 cases of scalp porocarcinoma as described in literature. ${ }^{1}$ However, porocarcinoma in frontoparietal region has not been described. Our patient had frontoparietal porocarcinoma, free from underlying bone and pericranium.

Clinically, the tumour may present as a verrucous plaque, polypoid growth or an ulcerative lesion of long duration and is to be differentiated from cylindroma (turban tumor), eccrine poroma, sebaceous adenoma, sebaceous carcinoma, pilar tumor of the scalp and metastatic carcinoma. Local recurrence (25\%) and metastasis to skin, local lymph nodes, breast, liver, bladder, ovary, adrenal glands, lung, peritoneum and bone may occur. ${ }^{1}$

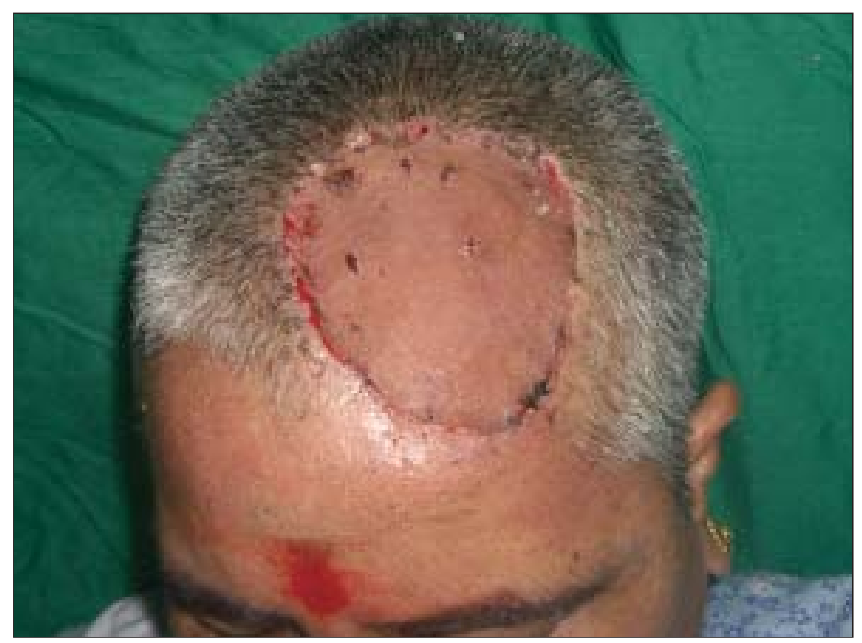

Figure 3: Raw area covered with a split-thickness skin graft 
Microscopic appearance ${ }^{7}$ in a primary tumor will show an asymmetrical tumor with cords and lobules of polygonal cells. Tumor cells may be limited to epidermis or may extend into dermis. Some islands of tumor cells may lie free in the dermis and there will be cystic lumina within tumor nests. There is nuclear atypia with frequent mitosis and necrosis. Epidermis may show acanthosis. Eccrine differentiation is indicated by spiralling ductular structures, ducts lined by cuticular material, zones of cytoplasmic glycogenation, intraepidermal cells in discreet aggregates often centred on acrosyringeal pores. Stroma may be fibrotic, hyalinised, highly myxoid or frankly mucinous. Malignant porocarcinoma in a poroma, on microscopy, will show areas composed of eccrine poroma cells with a benign appearance adjoining areas of anaplastic cells. Malignant cells have large hyperchromatic, irregularly shaped nuclei and may be multi-nucleated and are rich in glycogen. ${ }^{7}$ Our patient had a history of a quiescent swelling of long duration and diagnosis was made only on histology - infiltrating tumor with lobular configuration, glandular and cribriform pattern, abnormal mitosis, keratinization and mucinous metaplasia of stroma.

Immunohistochemical studies, namely, P53 protein expression study, expression of angiotensin type 1 receptors and expression of CEA, if possible, should be done to confirm the diagnosis. ${ }^{3,5}$

Treatment is wide local excision. ${ }^{1}$ Mohs micrographic excision has also been reported with a successful outcome. ${ }^{3}$ If regional nodes are involved regional lymphadenectomy should be done. ${ }^{1,3}$ Metastatic lesions can be treated with chemotherapy. Oudit et $\mathrm{al}^{4}$ have mentioned use of Melphalan, intra-arterial infusion of 5fluorouracil and hyperthermia. Perilesional injection of interferon-alpha and interleukin-2 has been reported to produce a partial response. ${ }^{4} \operatorname{Arslan}^{3}$ has mentioned use of docetaxel, interferon-alpha 2a and isotretinoin. DaSilva ${ }^{6}$ has reported a successful outcome with post-operative radiotherapy in recurrent cases.

More than 100 cases of porocarcinoma have been described in literature, ${ }^{3}$ of which less than 10 cases have been of scalp porocarcinoma. There is no case reported in literature of porocarcinoma on the frontoparietal region, not involving pericranium akin to our case.

\section{REFERENCES}

1. Ritter AM, Graham RS, Amaker B, Broaddus WC, Young HF. Intracranial extension of an eccrine porocarcinoma. Case report and review of the literature. J Neurosurg 1999;90:138-40.

2. Matloub HS, Cunningham MW, Yousif NJ, Sanger JR, Romano JA. Choi Hongyung:Eccrine porocarcinoma. Ann Plast Surg 1988;20:351-5.

3. Arslan E, Tatar C, Aksy A, Tutuner N. Denovo malignant eccrine poroma of the nose: A review of the midface as a location. Plast Reconstr Surg 2004;113:2227-9.

4. Oudit D, Ellabban M, Vuppalapati G, Stringfellow H, Korashi A. Porocarcinoma? Plast Reconstr Surg 2004;113:2216-7.

5. Hara K, Kamiya S. Pigmented eccrine porocarcinoma. A mimic of malignant melanoma. Histopathology 1995;27:86-8.

6. Dasilva MF, Terek R, Weiss AP. Malignant eccrine poroma of the hand. A case report. J Hand Surg 1997;22:511-4.

7. Elder D, Elenitsas R, Ragsdale BD. Tumors of the epidermal Appendages. In: David et al. Lever's histopathology of skin. $8^{\text {th }}$ Ed. Philadelphia: Lippincott Raven publishers; 1997. p. 780-3. 